\title{
ETSIT-UPM Experiences in Hands-on Nanosatellite Activities
}

\author{
Ramón Martínez \\ ETSI de Telecomunicación (ETSIT-UPM) \\ Universidad Politécnica de Madrid (UPM) \\ Madrid, SPAIN \\ ramon@gr.ssr.upm.es
}

\begin{abstract}
In this paper, the experience of ETSIT-UPM in handson nanosatellite activities is presented. Innovate methodologies based on the active participation of students are presented. Projects with the participation of students have proven to be successful if students are motivated and assume responsibilities. Aspects as international collaboration and students motivation are described.
\end{abstract}

Keywords- cubesat; nanosatellite; hands-on projects; international collaboration; student motivation

\section{INTRODUCTION}

A CubeSat is a small satellite with a cube form whose side is $10 \mathrm{~cm}$ and weight below $1 \mathrm{~kg}$. It was conceived in the late 90's by Prof. Robert Twiggs and Prof. Jordi Puig-Suari means to bring space technology to engineering students willing to develop a satellite by their own means with a reduced costs and in 2-3 years time [1][2]. Cubesat projects have become a standard de facto in the Universities providing space technology degrees.

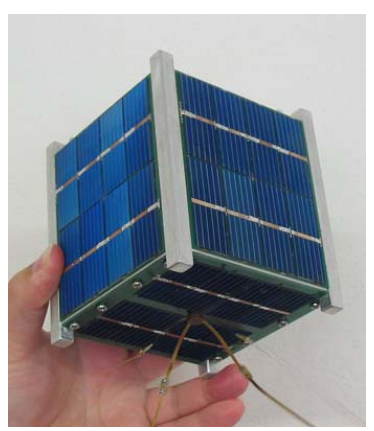

Figure 1. Cubesat.

Since its conception, cubesat projects have multiplied in many Universities worldwide as a means of innovative education promoting hands-on projects between students. From a learning perspective, cubesat projects join multidisciplinary students with diverse backgrounds that work together to reach a common objective.

Although with limited resources of mass, power and volume, a number of CubeSats have been implemented and launched for scientific (measurement of radiation, sensing) to communications (IP protocols in Space) and technology demonstration missions [3].
As a consequence, innovative methodologies must be implemented so that the participation of young students is essential to come up with original ideas and new concepts.

ETSIT-UPM started cubesat activities in 2008 [4]. In this paper we present the experience resulting from these activities making emphasis on the achievements performed by a number of students. The initiative has been supported by Universidad Politécnica de Madrid (UPM) and ETSI de Telecomunicación (ETSIT) in the form of an innovative education project called TelCUBE ${ }^{1}$.

Cubesats as well as space technology have evolved significantly in the last years and students have tackled larger projects such as nanosatellites under $10 \mathrm{~kg}$ based on the cubesat standard. Moreover, nanosatellites have gone one step further and are used now in experimental and technology validation missions [5].

Due to the number of international initiatives, CubeSat projects have an inherent worldwide and multicultural dimension that offer an extra motivation for the involved students.

The paper is organized as follows. In section II, TelCUBE project will be presented. Section III will describe the motivation and background that lead to the implementation of nanosatellite activities. As well, three main activities will be explained. The first one is the participation of students in the Mission Idea Contest (MIC) 2011 that will be explained in section IV. Section V presents the elaboration of a proposal for an international project such as QB50. The third activity in section VI deals with the set-up of a ground station for university satellites operation. The three activities stand out for their international dimension. Finally, section VII draws the conclusions of the paper.

\section{TelCUBE ProjeCt}

TelCUBE is a Project in Innovative Education for the implementation of space related activities in ETSIT-UPM. In TelCUBE, the main emphasis is put on the small satellite activities with a special focus on nanosatellites and CubeSats.

\footnotetext{
${ }^{1}$ http://telcube.blogspot.com
} 
TelCUBE is supported and funded by Universidad Politécnica de Madrid and the ETSI de Telecomunicación under the innovation activities programs.

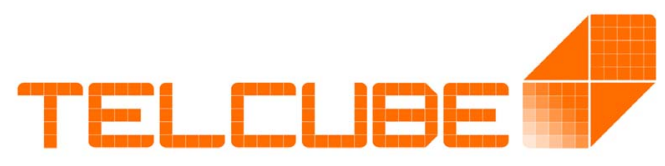

Figure 2. TelCUBE $\log 0^{2}$.

TelCUBE is formed by a group of highly motivated students and Faculty staff. Some experts from the industry have also expressed their interest in participating in TelCUBE meetings. Special emphasis has been put in the participation of students in international meeting, conferences and other events as a means to improve their knowledge in space technology.

The strategic objectives of TelCUBE are:

- Promote the participation of students in space technology activities and in particular nanosatellite projects

- Make students be aware of their professional opportunities in the space sector

- Support entrepreneurship initiatives that lead to new companies founded by students and academic staff

TelCUBE started formally in 2008 and since then a number of activities have been initiated. The activities carried out in the framework of TelCUBE can be summarized in:

- Participation in an International Contest with excellent qualification

- Celebration of working meetings with students to develop new concepts

- Organization of seminars and workshops in space technology with the active participation of students and experts from space industry

- Promote the participation of students in the preparation of proposals for joining international space consortiums

- Set-up of a ground station with remote control access to be used as a lab for students

TelCUBE has also promoted entrepreneurship activities between students and faculty members and part of the team received a prize to one of the Best Business Ideas for Technological Spin-Offs within the actuaupm contest organized by UPM in 2010.

\section{MOTIVATION AND SCENARIO}

The motivation for the set-up of a cubesat project in ETSIT-UPM relies in several reasons. First, it gives the students the opportunity to participate in a hands-on project leading to a complement in their theoretical lessons. It also implies a differential aspect in their curricula.

\footnotetext{
${ }^{2}$ TelCUBE logo has been created by Pablo Álvarez Vinagre.
}

Another of the main attractive of cubesats for students is the possibility to launch the satellite by an affordable cost $(50 \mathrm{k}-$ $150 \mathrm{k} €)$.

Cubesat projects are multidisciplinary. It means that students with different backgrounds (Orbital Mechanics, Computer Science, Communications, Electronics, Mechanical Engineering, Control, Physics) participate leading to a complement in their knowledge. It also emphasizes the discussion activities and the work in groups.

As well, cubesat projects are organized internally as professional space projects with standard methodologies, documentation, configuration control, project milestones and reviews. During the whole project, a large effort is put on the reporting and documentation including minutes of the meeting, progress reports, technical documentation, which lead to the efficient transfer of knowledge between successive student teams.

Moreover, thanks to the international dimension of cubesat projects, students have had the opportunity to work with other students from other Universities worldwide. As an example international collaborations with Latin American Universities and attendance to the $2^{\text {nd }}$ QB50 workshop are some of the examples.

From United Nations Office for Outer Affairs, small satellite activities are conceived as a means to support capacity building and sustainable development in developing countries using international cooperation. As an example, HumSAT ${ }^{3}$ project is an initiate supported by ESA and United Nations to develop a satellite-based system for connecting a set of users with a network of worldwide distributed sensors which they have previously deployed. Applications of interest for developing countries such as water pollution telemedicine, climate change monitoring, emergency beacon localization, etc. have been identified.

In the annual UN/ESA Small Satellite Symposium, TelCUBE activities in relation to cooperation with other Universities in Latin America were presented in 2011 [6].

The support of European Space Agency and strengths of the space industry provides another reason for implementing the project. This support is mostly providing technical support, implementing contests and organizing workshops and seminars that serve as networking events.

However, cubesat projects suffer from the lack of funding and the delays inherent to space projects. Because of that, the programmatic issues and an appropriate management team and methodology are essential for the success of the cubesat project.

\section{PARTICIPATION IN THE Mission IdeA CONTEST 2010}

The celebration of the Mission Idea Contest in 2010 gave ETSIT-UPM students an opportunity to participate in a international contest. It consisted in the proposal of an original idea related to the use of nanosatellite constellations to provide services and data beneficial for the society.

\footnotetext{
${ }^{3}$ http://www.humsat.org
} 
The contest consisted in preparing an abstract (in English) proposing an innovative idea for the use of nanosatellite constellations. The prize of the contest consisted in a visit to Tokyo to participate in the $2^{\text {nd }}$ Nanosatellite Symposium and present their work if qualifying as finalists.

The sessions for preparing the abstract started with discussions between students and the academic supervisor (Prof. Ramón Martínez) to present, evaluate and discard/accept an idea. Before accepting an idea, it was discussed by the students in order to detect lack of originality and technical feasibility. After four brainstorming sessions, three ideas selected and students were divided in three groups to prepare the three abstracts that were prepared under the supervision of the academic coordinator and were successfully submitted by the deadline.

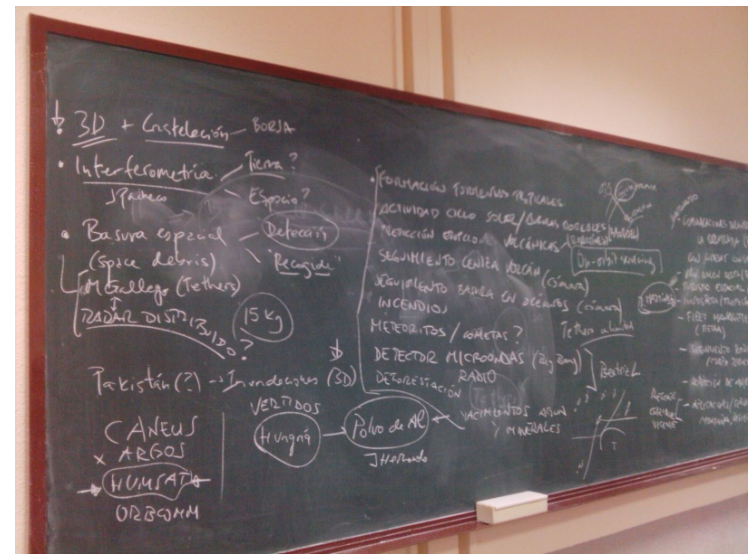

Figure 3. Blackboard after a TelCUBE brainstorming session.

After evaluation of proposals, one of the student teams was invited to travel to present the idea thanks to its qualification as semifinalist. The other two proposals did not obtain any prize by the organization but received the congratulations of the review team. 62 proposals from teams in 24 countries were submitted. Some of the teams were formed by staff from space companies whereas other proponents were University students as in the case of TelCUBE.

As a curious note, it is noticeable to mention that some of the finalist ideas were discussed during the preparation of the proposals.

The main outcomes to highlight are the high motivation of students and the possibility students have had to write a book chapter with a description of the mission idea [7]

The semifinalist idea entitled FALCON (Fire Alarm Constellation) proposed a nanosatellite constellation for the detection of fires making use of a combination of infrared and visible cameras on-board (Figure 5). Thanks to the on-board processing and the use of ground station network, early warning and monitoring of existing fires would be performed. Apart from the technical solutions, the team also showed the programmatic feasibility and an analysis of the main risks of the mission.

As shown in Figure 4, ETSIT-UPM students had the opportunity to present their project in the $2^{\text {nd }}$ Nanosatellite Symposium in Tokyo in 2011.

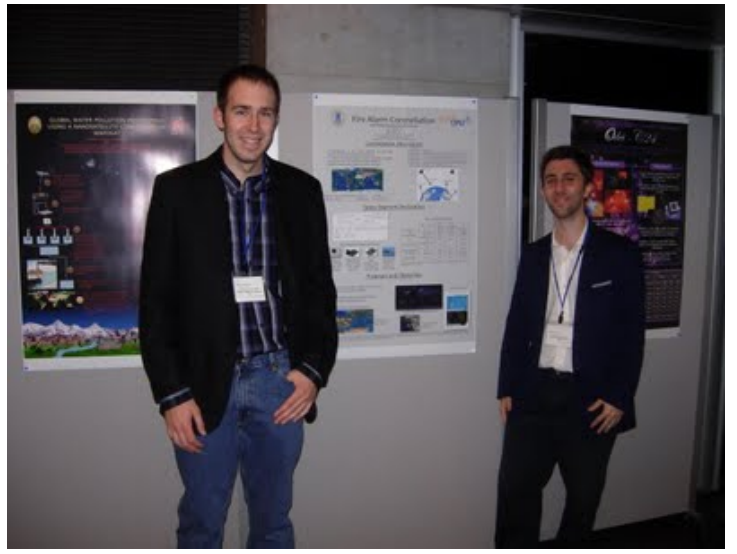

Figure 4. ETSIT-UPM students presenting their work in the $2^{\text {nd }}$ Nanosatellite Symposium (Tokyo, 2011).

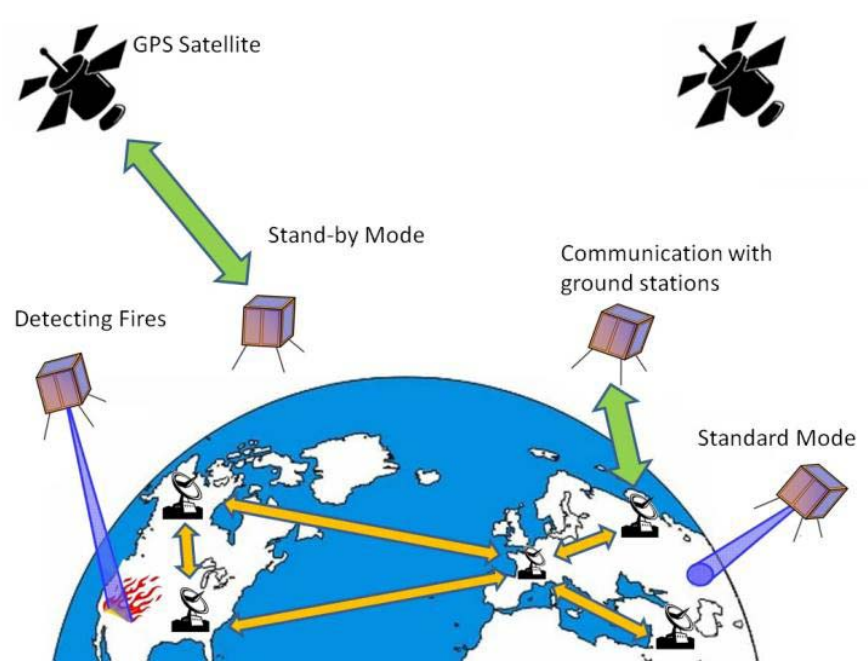

Figure 5. The FALCON concept.

\section{ElLABORATION OF A PROPOSAL FOR QB50}

The second activity is the elaboration of a proposal to be submitted to QB50 ${ }^{4}$. It is a European projects for the study of the thermosphere by means of a 50 nanosatellite constellations implemented from Universities and Research Centres worldwide. Participating 2U cubesats must carry a sensor provided by the project organization and must develop an adequate functional unit. The remaining volume, mass and power can be used to introduce a mission selected by each participating University or Institute.

Thanks to the experience gained in the participation in MIC, students are prepared to participate in a hands-on project such as QB50. A working group formed by students and academic staff is presently preparing a technical and managerial proposal to be submitted in the following months after the announcement of the definitive Call for Proposals.

As part of the activities for the preparation of the proposal, some research activities have been performed in order to find a suitable and attractive mission. The main activity is the

\footnotetext{
${ }^{4}$ http://www.qb50.eu
} 
feasibility evaluation of a mission to demonstrate the intersatellite link concept. In this topic, some advances in the design of antenna have been carried out with the participation of a student. The antenna concept was successfully presented in [8] and is shown in Figure 6.

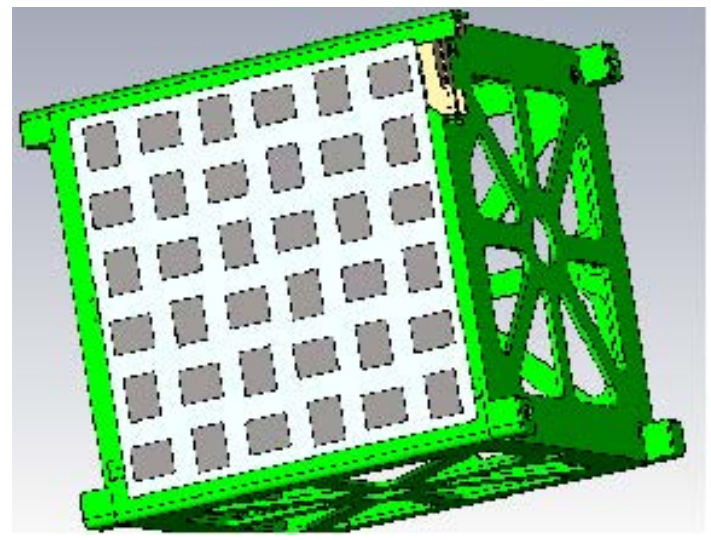

Figure 6. Modular antenna concept of intersatellite communications.

The participation in QB50 Workshops has open the possibility to be part of the Ground Station and Frequency Allocation Working Group of the Project.

\section{INSTALLATION OF A GENSO GROUND STATION}

Currently, students are participating in the set-up of a ground station for the tracking of University satellites operating in VHF and UHF bands. In the initial approach, the station will operate as a receiving node, and in future upgrades it will be operated as transmitter (the station is installed and designed from the beginning with the necessary equipment).

The installation of the station is carried out in the framework of GEOID (GENSO Experimental Orbital Initial Demonstration), the ESA driven contribution to HUMSAT. GEOID is a project supported by the ESA Education Office that will be used to validate the GENSO network to support in constellations of educational satellites.

GENSO ${ }^{5}$ (Global Education Network for Satellite Operations) is a project endorsed by the International Space Education Board (ISEB), and coordinated by ESA Education Office. GENSO aims at creating a global network of ground stations formed by university and amateur satellite stations to support the operations of university satellites [9].

With the participation in this activity, students will benefit from the following aspects:

- International dimension (1): the station will be part of GENSO: it is an educational project supported by European Space Agency (ESA). Therefore, students must face revisions of the design coming from ESA and will benefit from the reviews of their work coming from ESA experts.

- International dimension (2): other Universities with active satellites will be interested in using ETSIT-UPM for downloading data from their satellites. It will lead

\footnotetext{
${ }^{5}$ http://www.genso.org
}

to international cooperation activities and will make students work with students and researchers from other Universities by exchanging information, evaluating feasibility, etc.

- Horizontal capabilities: students have the opportunity to reinforce their skills in the area of writing technical reports, performing technical presentations, technical discussion with people from other Universities, meeting deadlines and requirements, etc.

During the initial phase, students have participated in the selection of an appropriate site for the installation of the antenna, search of equipment and distributor and writing of a technical report that has been submitted to ESA Education Office for the review and feedback. Students have also participated in the link budget study that has lead to appropriate selection of commercial antennas and radios.

Figure 7 shows the participation of students during the activities for the selection of the site for the antenna of the ground station. Apart from link budget analysis, aspects such as electromagnetic environment, obstacles, access to the cables and antennas, security for the installation must be taken into account prior to selection of the site. Students thus learn to evaluate different trade-offs and make decisions based on available information.

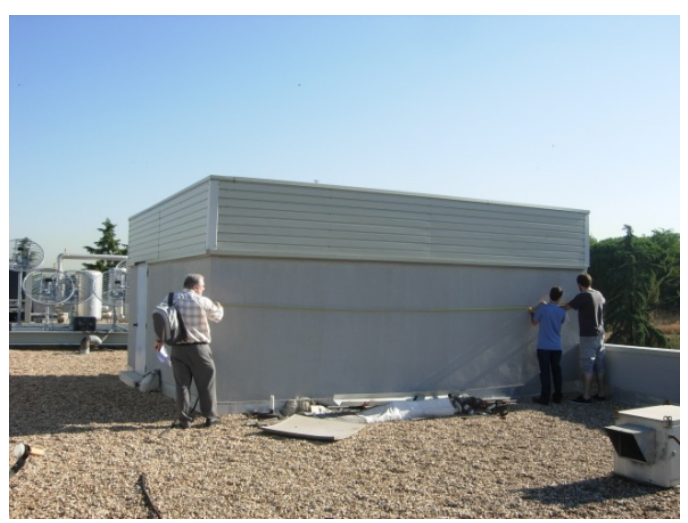

Figure 7. ETSIT-UPM students during antenna site selection campaign.

After the installation of the station, it will serve as part of the GENSO network, but also as a laboratory were students will have the possibility to learn about antennas, tracking, small satellites operation.

\section{CONCLUSIONS}

As a conclusion, it is important to remark that in spite of the lack funding, ETSIT-UPM has successfully implemented the initial phase of a cubesat project with extremely promising results for students. It can also be stated that the motivation of students has a larger impact on the success of the project than its technical expertise. This expertise is acquired during the project while motivation must be an initial resource.

Some important milestones have been achieved during the initial phase of TelCUBE. The most important one is the qualification as semifinalist in an international mission idea contest with a proposal implemented by students under the supervision of a faculty professor. 


\section{ACKNOWLEDGMENT}

Author would like to thank the TelCUBE team, students and faculty professors, for their participation and support in the project.

\section{REFERENCES}

[1] H. Heidt, J. Puig-Suari, A. S. Moore, S. Nakasuka, and R. J. Twiggs, "CubeSat: A New Generation of Picosatellite," in Proceedings of the $15^{\text {th }}$ Annual AIAA/USU Conference on Small Satellites, Logan, UT, August 2001.

[2] Cubesat Design Specification, Rev. 12. Cal Poly, 1999.

[3] S Greenland, C Clark, "CubeSat Platforms as an On-Orbit Technology Validation and Verification Vehicle," 2010 European Small Satellite Services Symposium, Madeira, 31 May - 4 June 2010.

[4] Ramón Martínez Rodríguez-Osorio, Miguel Calvo Ramón, Salvador Landeros Ayala, Francisco Javier Jiménez Leube, "TelCUBE: Implementation of a Project-Based Learning for the design of a picosatelltie," in Proc. VII Jornadas de Innovación Educativa, Universidad Europea de Madrid, 6-7 Sept. 2010.

[5] A. Schwarzenberg-Czerny, "The BRITE Nano-Satellite Constellation Mission," in Proc. 38 $8^{\text {th }}$ COSPAR Scientific Assembly, 18-15 July 2010, Bremen, Germany, p.15.

[6] Ramón Martínez, "International University Collaboration for the Development of Small Satellites Activities," United Nations / Austria / European Space Agency Symposium on Small Satellite Programmes for Sustainable Development "Implementing Small Satellite Programmes: Technical, Managerial, Regulatory and Legal Issues", Graz, Austria, 13 - 16 September 2011.

[7] J. Hernando, M. Gallego, R. Martínez, Chapter 11: "Fire Alarm Constellation," pp. 122-132, Mission Idea Contest for NanosatelliteConstellation (MIC), to be published in 2011.

[8] E. Fueyo, R. Martínez, "Design of a patch antenna array for communication between cubesats," in Proc. 1st IAA Conference on University Satellites Missions and Cubesat Workshop, Rome, 24-29 January, 2011.

[9] Bastian Preindl, Naomi Kurahara, Kamil Kaczmarek, Ivo Klinkert, Lars Mehnen, Viktor Nikolaidis, Helen Page, "Global Educational Network For Satellite Operations (GENSO)," $60^{\text {th }}$ International Astronautical Congress, Daejeon, Republic of Korea, 12-16 October 2009. 